\title{
https://doi.org/10.48009/1_iis_2006_231-235 \\ PREPARING FOR THE SERVICE CALL: CIS FACULTY IN THE GENERAL STUDIES PROGRAM
}

\author{
Lynn R. Heinrichs, Elon University, lheinrichs@elon.edu \\ Michele Kleckner, Elon University, mkleckne@elon.edu
}

\begin{abstract}
In today's environment, many schools are placing emphasis on transforming undergraduate education through innovative general studies programs. Computing faculty members may find themselves in unfamiliar territory when asked to teach a course outside of their discipline. What questions should faculty consider before answering the service call? The authors describe experiences at their own institution involving an interdisciplinary course entitled, "The Global Experience." Differences in time requirements, pedagogy, and student audiences are discussed. Implications for junior faculty are considered.
\end{abstract}

Keywords: Curriculum, General Education, General Studies, IS Faculty, Service

\section{INTRODUCTION}

Faculty in computer information systems (CIS) and computer science (CS) are not new to the general education program on most campuses. For years they have been asked to deliver computer literacy courses. In today's environment, many schools are placing emphasis on transforming undergraduate education through innovative general studies programs. Computing faculty members may find themselves in unfamiliar territory when asked to teach a course outside of their own discipline.

In this paper, the authors describe the first experience of the CIS faculty in teaching a general studies course at their institution. The interdisciplinary course, entitled "The Global Experience," is required of all freshmen. Departments from across the university are asked to support the general studies program by delivering multiple sections of the course each year. Beginning in 2004-05, the authors' department was asked to contribute two sections in the fall semester each academic year.

There are several questions a CIS faculty member should consider before answering a similar service call:
- What are the differences in teaching IS vs. general studies?

- Does participation in general studies enhance or detract from teaching in the discipline?

- Should junior faculty teach in general studies?

The paper addresses each of these questions within the context of the authors' experiences. The discussion is of interest to faculty and department heads with potential responsibility for the general education program at their institutions.

\section{THE ROLE OF COMPUTING FACULTY IN GENERAL EDUCATION}

\section{Traditional Role: Computer Literacy}

Computing programs, both CS and CIS, traditionally have played a role in undergraduate general education. Computer science programs frequently offer a non-major course that can be used to meet a requirement in natural science, mathematics, or computer literacy. For example, Leska [7] described the use of robots to teach undergraduates about programming in the general education curriculum. Stegink, Pater, and Vroon [14] outlined a general education computer science course that included Java, graphics, and the Web. Marks, Freeman, and Leitner [9] reported on a case-based approach for teaching computing without programming. No matter what pedagogy is applied, faculty members typically are interested in finding new and innovative ways of approaching the general education course.

Computer literacy courses offered by CIS programs have also been found in general education curricula. Such courses tend to focus more on application software and information technology concepts than pure programming. For example, Bretz and Johnson [2] described introduction of a self-paced computer literacy course delivered via the Web that covered software applications and general concepts. Hindi, Miller, and Wenger [5] surveyed students enrolled in a required introductory microcomputer course about their perceived literacy. Rao, Keefe, and Shah [12] examined 63 business schools and found that about one-fifth of all schools that offered a computer 
literacy course did so for a university-wide requirement.

Departments offering either non-major or computer literacy courses often see an opportunity to recruit majors to their programs. Efforts related to continuous improvement and innovation are frequent topics of conference papers. Faculty members are always looking for new approaches to enhance the attractiveness of their general studies offerings.

While computer literacy courses can be challenging from a pedagogical perspective, faculty are still operating within the boundaries of their discipline. Computer science departments focus on programming concepts. Information systems departments emphasize application software and computer concepts. In either case, the content is familiar territory, and faculty can remain in their comfort zones.

\section{New Role: Interdisciplinary Studies}

O'Meara, Kaufman and Kuntz [11] identified "reform in undergraduate education" as one of four trends in higher education. Specifically, the authors identified major shifts in the areas of diversity, technology, and student affairs/academic affairs partnerships. The latter partnerships have fostered collaborative programs such as "service learning, field experiences, team teaching, and residential living-learning communities."

General education makes up about $25 \%$ of an undergraduate program [13]. As students compete in today's global environment, the content of the general education program is constantly under review. The results of a 2001 AAC\& U study [13] found that $78 \%$ of institutions reported changes to general education curriculum in the 1990s. Favored curricular changes included freshman seminars $(55 \%)$, interdisciplinary courses $(55 \%)$, and common learning experiences $(49 \%)$.

According to Holyer [6], the "ultimate goal of general education is engagement and improvement in fundamental ways to identify and analyze intellectual problems (including finding, evaluating, and using factual information), rather than a factual coverage approach (p. 45)." At the authors' institution, the general studies program is intended to provide "students with opportunities to see the broad view of human civilization, experience great ideas and art and learn the science and math skills without which no contemporary leader or individual can be without." The program is intended to span the entire college career, "challenging students, preparing them for both leadership and independent thought . . . deepening and enriching their lives."

One of the traditional problems in delivering a general education program has been faculty engagement. McGrath [10] reported on Harvard's effort to revise general education and described the following obstacle:

. . . a lot of faculty members don't particularly want to teach them anymore; they're timeconsuming, labor-intensive and usually have little to do with a teacher's specialty; and it's by excelling in your specialty, not by starring in the classroom, that you advance your career in academe.

When universities hire new faculty, they hope to promote good teaching, quality research, student learning, university loyalty, innovation, teamwork, and interdisciplinary work. What they often reward are research publications, good grades, established approaches, individual accomplishments, and departmental achievements [16].

Gerdes [4] writes about the general dangers of disciplinary loyalties to liberal education programs. Among those mentioned include faculty "lack of confidence in their own ability to teach outside what they have defined as their own disciplinary or interdisciplinary field (p. 51)." Stearns [13] recognizes that the problems of faculty engagement are not new, but problems can be addressed "with a shift in faculty culture and a new level of commitment from academic administration (p. 47)."

\section{A CASE STUDY IN TEACHING GLOBAL STUDIES}

As institutions move forward in revising general education programs, computing faculty can expect to be called to serve in some capacity, perhaps teaching a freshman seminar or an interdisciplinary studies course. What questions should a faculty member consider when answering the service call? The authors identified the following from their own experiences:

- What are the fundamental differences between teaching a discipline-based course and teaching a general education course?

- Does attention devoted to general education enhance or detract from one's ability to serve his/her discipline? 
- Should junior faculty avoid teaching in general studies?

The authors are CIS faculty at an institution that requires a four-hour, interdisciplinary course of all freshmen entitled GST110, The Global Experience. The course description for GST110 is as follows:

This first-year seminar examines public responsibility in a global context. It explores some of the implications created by cultural and natural diversity and the possibilities for human communication and cooperation within this diversity. The course emphasizes student and faculty creativity through active and collaborative learning; the seminar is writing intensive.

Departments from across the university are asked to support GST110 by delivering multiple sections of the course each year. Beginning in 2004-05, the authors' department was asked to contribute two sections in the fall semester each academic year. Whoever is assigned responsibilities for teaching GST110 makes a two-year commitment to the course that includes not only course preparation and delivery, but regular meetings during the school year and summer session aimed at coordinating and supporting GST110 faculty.

\section{What are the Differences in Teaching GST versus CIS?}

Based upon the authors' experiences, the primary differences between teaching CIS and GST are (1) preparation time, (2) overhead time, (3) pedagogy, and (4) student audience.

Preparation Time. The mindset for teaching GST110 is much different than for teaching CIS courses. First of all, preparatory time is much greater for GST110. Instructors are given six main themes for teaching, but textbooks vary based upon the faculty's discretion. The six main themes are: (1) the importance of individual responsibility, (2) the relationship of humans to the natural world, (3) globalization and tribalization as powerful global forces, (4) the impact of imperialism and colonialism, (5) the nature of culture, and (6) the plights of disempowered groups.

Developing a plan to help the students understand these six themes takes a considerable amount of time. Each year a committee of students and faculty select a book for all incoming students to read. There is an expectation that all students will have read this book and that faculty members will use it as a basis for discussion and writing assignments. Past common reading books include Falling Leaves [8] and Nickel and Dimed: On (Not) Getting By in America [3]. Each fall these authors are brought to campus as guest speakers. The subject matter from the common reading and guest speakers greatly influence the plan for the semester. Successfully interweaving class readings and assignments with campus events that touch on each of the six main GST110 themes is a difficult task that must be reevaluated each semester.

GST110 assignments are expected to integrate the six themes. Faculty must prepare a diverse set of assignments to achieve this. For example, the theme of globalization might be integrated by having students participate in a model United Nations exercise. Most CIS faculty would not have a file drawer full of these types of assignments. Fortunately, those who volunteer to teach GST110 find an extensive support network of other faculty. Many successful assignments are available and well documented.

Overhead Time. As previously mentioned, faculty members who commit to teaching the GST course meet regularly during the semester. The meetings are aimed at providing instructional support as well as coordination of efforts. At the beginning of each semester, a two-day workshop is held for faculty to discuss teaching expectations such as academic challenge. Common readings or experiences, speakers, and syllabi guidelines are also discussed. During the regular semester, there are weekly, onehour lunch meetings. Topics include concerns such as projects and student expectations. While teaching CIS courses also requires overhead time and faculty coordination, the scale is much smaller than that involved in teaching GST110.

Faculty members are encouraged to assign GST students work that involves attendance at many of the campus cultural events. While instructors are not required to be at these events, evaluating assignments that involve a lecture or performance is almost impossible without attending. In one author's syllabus, eight cultural events were presented for students to consider.

Pedagogy. Aside from preparatory time and overhead time, the next big difference in teaching GST110 over CIS courses is in delivery and grading. The role of a GST110 faculty member is more of a facilitator than a lecturer. Class discussions are more often student-led, and successful conversations depend upon the roles of each participant. Active 
participation (and attendance) is not only emphasized, but expected. GST110 is advertised as being both reading and writing intensive. Because of the subjective nature of grading papers (versus grading CIS projects), different evaluation methods must be considered. Rubrics and peer grading are particularly useful.

Student Audience. An interesting analysis of Higher Education Research Institute (HERI) data [1] compared personal attributes of freshmen students in computer science, engineering, and the social and behavioral sciences. Freshmen rated themselves on five attributes: intellectual self-confidence, social self-confidence, writing ability, public speaking ability, and popularity. The results for computer science and Behavioral \& Social Sciences (B\&SS) are shown in Table 1. Male students in the B\&SS scored themselves highest on all five attributes. Female students in the B\&SS scored themselves higher than both men and women in CS with one exception; men in CS rated themselves higher in intellectual self-confidence. In general, freshmen in CS have less perceived social confidence, writing ability, public speaking ability, and popularity than those in the B\&SS.

Table 1. Freshmen in Computer Science vs. the Behavioral \& Social Sciences

\begin{tabular}{|c|c|c|c|c|}
\hline Attribute & \multicolumn{2}{|c|}{ Computer Science } & \multicolumn{2}{|c|}{ Behavioral \& Social Science } \\
\hline & Men & Women & Men & Women \\
\hline Intellectual, self-confidence & 65 & 52 & 75 & 55 \\
\hline Social self-confidence & 45 & 42 & 60 & 50 \\
\hline Writing ability & 40 & 35 & 60 & 55 \\
\hline Public speaking ability & 25 & 22 & 53 & 40 \\
\hline Popularity & 35 & 30 & 53 & 40 \\
\hline
\end{tabular}

(Percent Either above Average or in Top 10\%)

While CS and CIS are not the same disciplines, the experiences of the authors are consistent with the findings of the HERI report. GST110 is a freshman course taught to all university students. CIS courses, on the other hand, are predominantly taught to CIS majors or minors. GST110, or "liberal arts," students tend to be more socially self-confident, better public speakers, and more philanthropic or civically engaged than CIS students. On the other hand, CIS students tend to be more intellectually self-confident, better active learners, and better problem solvers. Because of these characteristics, GST110 students are able to actively engage in group discussions and critically think about open-ended questions. CIS students, conversely, are better at well-defined problems.

As a result of differences in the student audience, an instructor can anticipate changing his/her teaching style when moving from CIS to GST. The types of assignments used to integrate the six themes create the type of engaging classroom environment that works well with a general studies audience.

\section{Does GST Enhance or Distract?}

A reasonable concern faculty members might have when asked to teach in general studies is whether or not it will detract from teaching in their disciplines. Teaching two sections of a general studies course certainly impacts the time available for conducting research. Scheduled meetings combined with class preparation and assignment grading can consume a substantial part of the work week. Pursuing a research agenda concurrently with teaching general studies would pose a challenge for many faculty members. CIS instructors have the additional burden of staying current with technology. This can also take a backseat to delivering a general studies course.

While time in the discipline is likely to be sacrificed, teaching in general studies has many rewards. First is the opportunity to gain a new perspective. Preparing and delivering a general studies course forces one to move beyond disciplinary boundaries. Second is the exposure to new teaching methodologies. Techniques used to engage students in general studies can be applied to CIS. Last of all is the interaction with other faculty from across campus. Teaching in general studies provides an opportunity to develop new colleagues and friends for future teaching and research endeavors.

\section{What Should Junior Faculty Do?}

When departments are asked to service general education courses, more enthusiasm might resonate from junior rather than senior faculty members. Junior faculty may feel a greater need to be team players and support departmental obligations. On the other hand, is teaching in general studies a good focus of attention for untenured instructors? 
The impact of teaching general education on research time has already been discussed. Depending on the mission of the institution, trading research time for general studies time could be disastrous for junior faculty. Untenured instructors under pressure to churn out publications could easily be distracted from their research agendas.

Department heads might also be concerned about the impact of general studies on teaching evaluations for younger faculty. A common perception among faculty is that those teaching general studies receive lower teaching evaluations than those focusing on their disciplines. Table 2 compares the average teaching evaluation for CIS and GST110 sections in Fall 2004 and 2005.

Table 2. Average Teaching Evaluations

\begin{tabular}{|l|l|l|l|}
\hline \multicolumn{2}{|c|}{ Fall 2004 } & \multicolumn{2}{c|}{ Fall 2005 } \\
\hline CIS & 4.08 & CIS & 4.29 \\
\hline GST & 4.25 & GST & 4.18 \\
\hline
\end{tabular}

The data for the two semesters shown does not support the concern about lower evaluations in general studies. However, this is a limited set of data and caution should be taken in making generalizations.

\section{CONCLUSIONS}

Given the continued interest in transforming undergraduate education on many campuses, CIS faculty can expect a future call to general studies service. In this paper, the authors described experiences at their own institution involving an interdisciplinary course entitled, "The Global Experience." Differences in time requirements, pedagogy, and student audiences were discussed. Implications for junior faculty were considered. While teaching in general studies can involve a significant commitment of time, it can also provide rewarding experiences such as exposure to other disciplines, new teaching methodologies, and faculty from across campus.

\section{REFERENCES}

1. Boylan, M. (date unknown). Characteristics of First-Time Freshmen in 4-Year Institutions Intending to Major in Engineering and Computer Science; an analysis of survey data collected by the Higher Education Research Institute (HERI), from http://www.nae.edu.

2. Bretz, R. and Johnson, L. (2000) An Innovative Pedagogy for Teaching and Evaluating Computer Literacy, Information Technology and Management 1, 283-292.

3. Ehrenreich, B. (2001). Nickel and Dimed: On (Not) Getting By in America, New York: Metropolitan Books.

4. Gerdes, E.P. (Summer 2002). Disciplinary Dangers, Liberal Education, 48-53.

5. Hindi, N.M., Miller D., and Wenger, J. (2002). Computer Literacy: Implications for Teaching a College-Level Course, Journal of Information Systems Education, retrieved on February 14, 2006, from http://www.findarticles.com/ p/arti cles/mi_qa4041/is_200201/ai_n9068240/pg_1.

6. Holyer, R. (Winter 2002). General Education \& Faculty Culture, Liberal Education, 36-41.

7. Leska, C. (2004). Introducing Undergraduates to Programming Using Robots in the General Education Curriculum, Proceedings of ITICSE04, p. 263.

8. Mah, A.Y. (1999). Falling Leaves, New York: Broadway Books.

9. Marks, J., Freeman, W., and Leitner, H. Teaching Applied Computing without Programming: A Case-Based Introductory Course for General Education, Proceedings of SIGCSE 2001, Charlotte, NC, 80-84.

10. McGrath, C. (January 8 2006). What Every Student Should Know, The New York Times, New York, NY, pg. 4A.33.

11. O'Meara, K., Kaufman, R.R., and Kuntz, A.M. (Fall 2003). Faculty Work in Challenging Times: Trends, Consequences, and Implications, Liberal Education, 16-23.

12. Rao, M., Keefe, J., \& Shah, V. (2006). Computer Literacy Courses in Schools of Business: To Be or Not to Be? Presentation at the Annual Meeting of the Southwest Decision Sciences Institute (SWDSI), Oklahoma City, OK.

13. Stearns, P. (Winter 2002). General Education Revisited, Again, Liberal Education, 42-47.

14. Stegink, G., Pater, J., and Vroon, D. (1999). Computer Science and General Education: Java, Graphics, and the Web, Proceedings of SIGCSE 1999, New Orleans, 146-149.

15. Thomas, J.R. (2003). Preparing for Faculty Roles in Discovery, Learning, and Engagement, Quest 55, 4-17.

16. Townsend, G.C. (1998). Turning Liabilities into Assets in a General Education Course, Proceedings of SIGCSE 98, 58-62 